\title{
A. C. Conductivity and Dielectric Study of Strontium Doped Lanthanum Manganite (LSM) thin films as Cathode for SOFC
}

\author{
B. S. Kamble ${ }^{1 *}$, V. J. Fulari ${ }^{2}$, R. K. Nimat ${ }^{3}$ \\ ${ }^{1}$ Department of Physics, D. B. J. College, Chiplun-415605, India \\ ${ }^{2}$ Department of Physics, Shivaji University, Kolhapur-416004, India \\ ${ }^{3}$ Department of Physics, Balasaheb Desai College, Patan-415206, India \\ *Corresponding Author: kamblebabaso@yahoo.com
}

Available online at: www.isroset.org

Received: 27/Sept/2018, Accepted: 19/Oct/2018, Online: 31/Oct/2018

\begin{abstract}
A.C. conductivity of LSM thin film prepared by spray pyrolysis technique and sintered at $900^{\circ} \mathrm{C}$ was measured at room temperature having various strontium concentrations. The results reveal that as strontium content increases a. c. conductivity increases. The experimental results of doped LSM thin films reveal that correlated barrier hopping $(\mathrm{CBH})$ model is the most suitable model to explain the a. c. conduction mechanism. The dielectric constant was measured keeping frequency constant with varying temperature and it is found that as temperature increases dielectric increases and after peak it decreases.
\end{abstract}

Keywords- Spray Pyrolysis, a. c. conductivity, Dielectric constant, Cathode, LSC, SOFC.

\section{INTRODUCTION}

Recently, many researchers have been working on designing solid oxide fuel cell (SOFC) cathode materials which will reduce the operating temperature. Special efforts has been dedicated to investigate cathode materials to ascertain the fact that the oxygen reduction to a reduced temperature ${ }^{[1-2]}$ will optimize optimize the porous cathode material such to an extent that the oxygen reduction reaction kinetics often significantly limits the performance of SOFC. The cathode polarization resistance and the microstructure of the cathode are closely related to each other. The reduction of polarization resistance of SOFC will be responsible for improving the performance of fuel cell. Perovskite metal oxides with composition of $\mathrm{La}_{1-}$ ${ }_{x} \mathrm{Sr}_{\mathrm{x}} \mathrm{MnO}_{3-\delta}$ (LSM) are most commonly used cathode material for SOFC, due to their high electro-catalytic activity, good chemical stability and electronic conductivity in oxidizing atmospheres ${ }^{[3]}$. Various deposition techniques have been used to deposit LSM thin films, such as atomic layer deposition, electro deposition, chemical vapour deposition, Sol-gel and spray pyrolysis ${ }^{[4-}$ ${ }^{8]}$. Among these methods, the spray pyrolysis is simple, cost effective technique. In the present study LSM thin film were synthesized by spray pyrolysis technique. A.C. conductivity and dielectric constant were studied for SOFC cathode.

\section{EXPERIMENTAL}

The LSM sample having $0.1,0.2$ and $0.3 \mathrm{~mol} \%$ were synthesized by spray pyrolysis technique by adjusting various parameters. Deposited thin films were sintered at $900^{\circ} \mathrm{C}$ for two hours. For taking the measurement, the sample is mounted on heating plate, and then two probes are electrically connected to the sample by highly conductive silver paste. A.C. conductivity of LSM materials was measured by using HIOKI LCR-Q meter. Dielectric constant was measured using HP 4384A LCR-Q meter by varying the temperature. 
III. RESULTS AND DISCUSSION
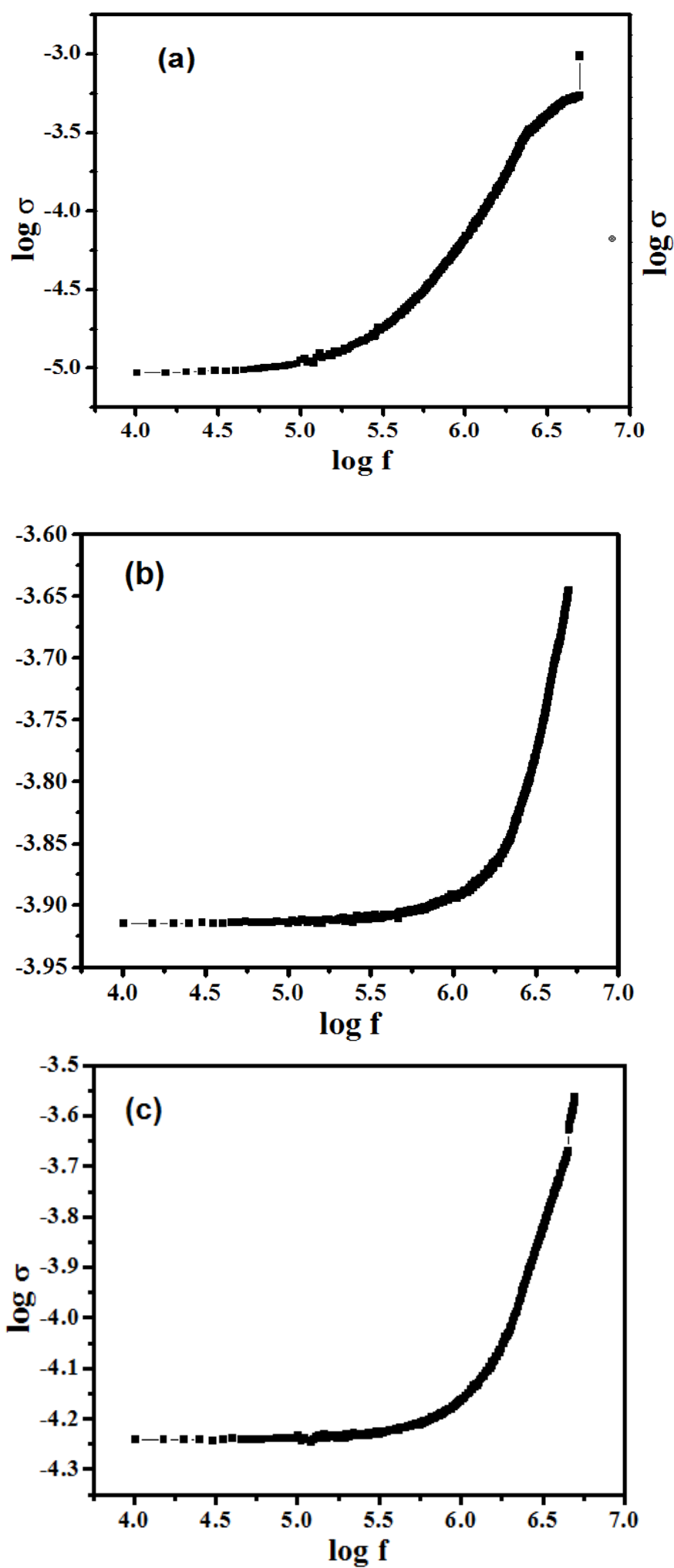

Fig. 1 A.C. conductivity of LSM thin films (a) $\mathrm{X}=0.1$, (b) $\mathrm{X}=0.2$, (c) $\mathrm{X}=0.3$
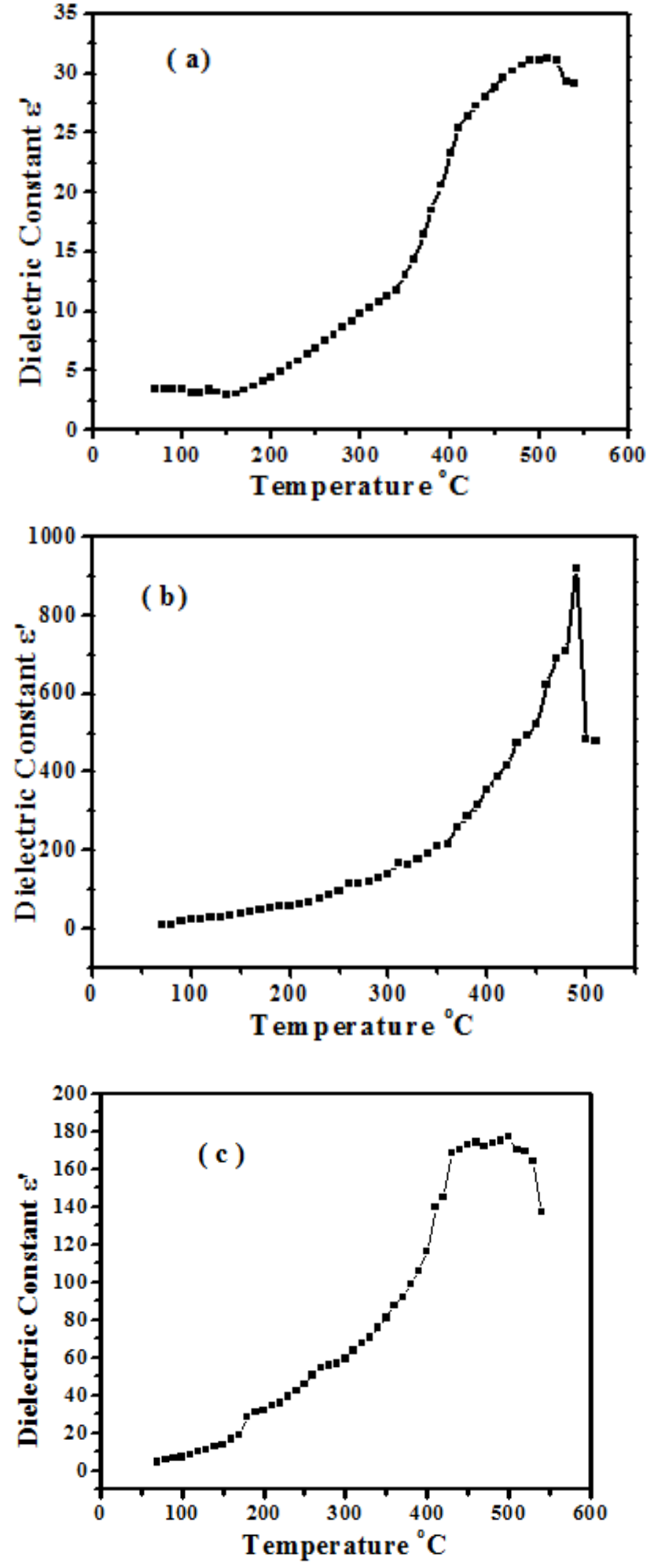

Fig.2. Variation of dielectric constant with temperature at $200 \mathrm{KHz}$

(a) $\mathrm{X}=0.1$, (b) $\mathrm{X}=0.2$, (c) $\mathrm{X}=0.3$ 


\subsection{A. C. Conductivity Studies}

Fig. 1 shows the variation of A. C. conductivity as a function of frequency. It is observed that as frequency increases conductivity slowly increases and at higher frequency it increases sharply. This increase in value of A. C. conductivity is due to the presence of space charge polarization ${ }^{[9]}$. At lower frequency plateau region correspond to the presence of D. C. conductivity of the composite materials. At lower doping concentrations of strontium, grain boundaries primarily act as scattering site and potential barriers leading to reduced carrier mobility by decreasing conductivity. At higher strontium doping concentrations, the conductivity was enhanced by energy levels. As a result the conductivity increased at higher doping concentrations.

\subsection{Dielectric Constant:}

Figure 2 exhibit the dielectric constant which varies w.r.t. temperature. The temperature varied from room temperature to $550^{\circ} \mathrm{C}$ at $200 \mathrm{KHz}$ frequency. The dielectric constant was approximately constant up to temperature $250^{\circ} \mathrm{C}$, but with the further increase in temperature dielectric constant reaches maximum and then decreases which were due to accumulation charges at the grain boundaries. At lower temperature, dielectric constant increases because at low temperature dipoles cannot orient themselves. As the temperature increases, the dipoles were easily oriented, which tend to increase dielectric constant. It was observed that rate of increase of dielectric with temperature was found to be highest for sample crystallized with increase strontium content. Due to growing effect of dipole polarization and ionic polarization dielectric constant slowly increases in temperature ${ }^{[10,11]}$, where comes into play relaxation time. With the further increase in temperature, relaxation time decreased and added the random vibrations to the molecules, which became less susceptible because of the molecules oriented with field direction and hence dielectric constant decreased.

\section{CONCLUSION}

The electrical properties like A. C. conductivity and dielectric constant of LSM thin film were studied. As strontium concentration increases A. C. conductivity increases and hence polarization resistance decreases. The high conductivity makes these LSM films as most proper cathode device for miniature SOFC to reduce the operating temperature. The dielectric constant increases up to certain temperature and with further increase in temperature dielectric constant decreases. This was due to accumulation charges at the grain boundaries of LSM particles.

\section{REFERENCES}

[1] Steele BCH, Heinzel A. Nature 2001, 414:345.

[2] Brandon NP, Skinner S, Steele BCH, Annual Review of Materials research 2003; 33:183.

[3] Young-Hoom Choi, Segoo Kang, Jurgen Wackerl, Kyoung-Tae Lim, Doo-Hwan Jung, Taejin Kim 7 Dong-Hyun Peck, J. Ceram. Process. Resear. (2013) 153.

[4] S.Sprering, D. Hariskos, M. Powalla, N. Naghavi, D. Lincot, Thin Solid Films, (2003) 431

[5] N. Revathi, P. Pratap, K. T. Ramakrishna Reddey, Solid State Sci, 11 (2009) 1288

[6] M. Abel Haleem, M. Ichimura, Thin Solid films, 516 (2008) 7783

[7] C. D. Lokhande, A. Ennaoui, P. S. Patil, M. Giersig, K. Diesner, M. Muller, H. Tributsch, Thin Solid Films, 340 (1999) 18.

[8] B. S. Kamble, V. J. fulari, R. K. Nimat, Inter. J. of sci. and Tech., (2016)

[9] P.Ganguly, Y. Vasanthacharya, J. Solid State Chem.61, (1986) 164.

[10] B. M. Tereev "Electrical and Radio Engineering Materials" MIR publishers, Moscow (1980)

[11] Khatri P, Behera B and Choudhary RNP, Structural \& Electrical Properties of Sr3V2O8 ceramics, Phys status Solidi B 2009; 246(5): 118. 